\title{
LATERAL DEFLECTION OF CANTILEVER SECANT PILE IN SOFT CLAY
}

\author{
الازاحة الجانبية للحوائط الحخازوقية الكابولية في التربة الطينية الضعيفة \\ DIF, A. ${ }^{1}$, IBRAHIM, A. ${ }^{2} \&$ ALLAM, R. ${ }^{3}$
}

\footnotetext{
${ }^{1}$ Professor, Structural Engineering Department, Faculty of Engineering, El-Mansoura University, Egypt.

${ }^{2}$ Assist.prof., Structural Engineering Department, Faculty of Engineering, El-Mansoura University, Egypt.

${ }^{3}$ Researcher Student, Structural Engineering Department, Faculty of Engineering, El-Mansoura University, Egypt.
}

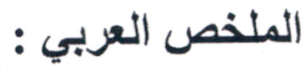

حالة التربة في الموقع والاجهادات الحقلية يتحكمان في اداء الحفر العميق، ومن احد انظمة سند الحفر العميق هو الحائط الحقا

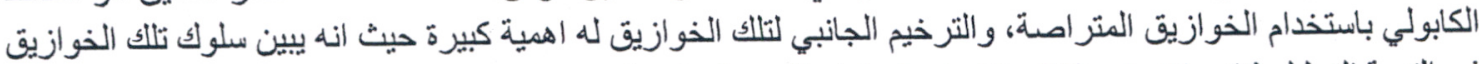

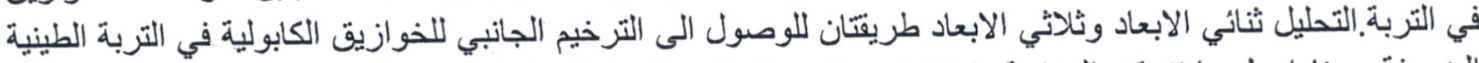

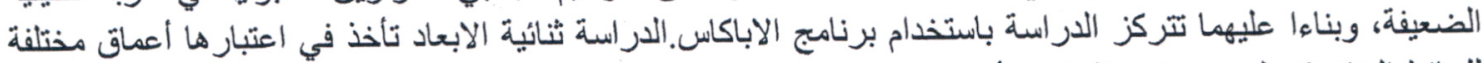

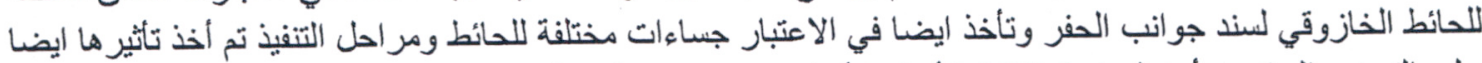

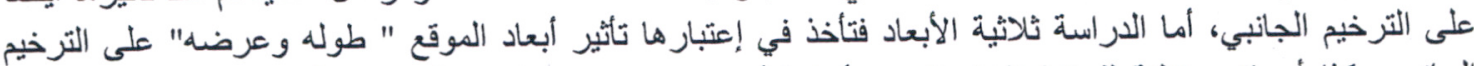

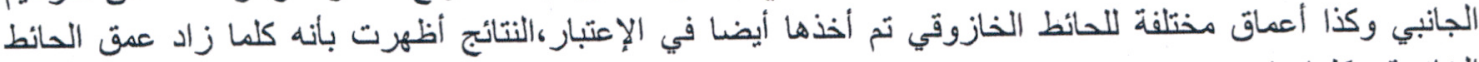

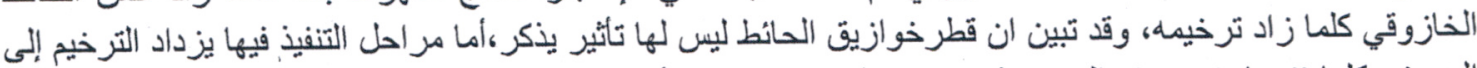

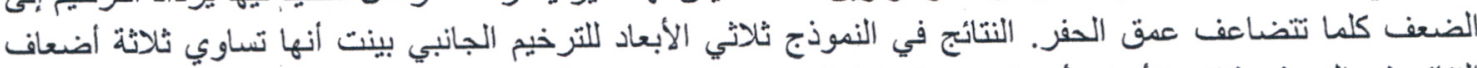

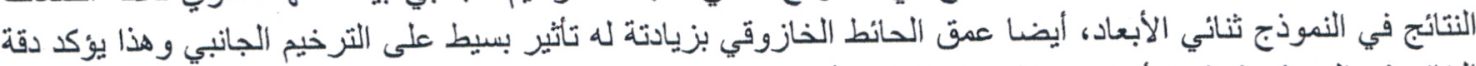

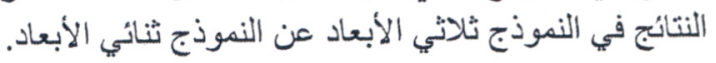

\section{ABSTRACT}

The performance of deep excavations is governed by the ground conditions such as soil stiffness and in situ stress conditions. Cantilever secant pile wall (CPW) is one of the retaining systems which are used to support deep excavation. Its lateral deflection has great importance as it shows the behavior of CPW in the soil. Two dimensional analysis (2D) and three dimensional analysis (3D) may be used to get the lateral deflection in numerical solution. This study is focused on $2 \mathrm{D}$ and $3 \mathrm{D}$ analysis for $\mathrm{CPW}$ in soft clay. The finite element software "Abaqus/CAE-v6.9" has been used in the analysis. The 2D study analysis takes into account the different CPW depths and its diameter effect. The construction stages effect on the lateral deflection have been studied also. The $3 \mathrm{D}$ study analysis takes into account the different excavation geometry "the length and width of the excavation" effect, also different depths for CPW in 3D analysis have been studied also. The results showed that longer CPW has larger lateral deflection while CPW diameters have no effect on lateral 
deflection. Lateral deflection in one construction stage may be double that of previous stage. Also it was found that lateral deflection in three dimensional (3D) analysis is higher than the $2 \mathrm{D}$ analysis by three times. This confirms that $3 \mathrm{D}$ analysis of CPW in soft clay leads to more accurate results than $2 \mathrm{D}$ analysis.

KEYWORDS: Cantilever Secant Pile; Retaining Systems; Soft Clay; Excavation; Lateral Deflection; Abaqus/CAE-v6.9

\section{INTRODUCTION}

Construction of retaining walls in urban areas has grown significantly over the last few decades. The magnitude and distribution of lateral deflection adjacent to an excavated wall is an important part of the analysis and design.

$3 \mathrm{D}$ effects caused by the higher stiffness at the corners of an excavation lead to smaller ground movements near the corners and larger ground movements toward the middle of the excavation wall due to the corners behavior as supports.

From that behavior, a conventional 2D simulation of the excavation gives results that differ from 3D simulations of the same excavation [1].

$2 \mathrm{D}$ analysis is commonly adopted to be applied to excavations when designing support systems and making estimates of associated lateral deflection. However, excavations behave in a manner more accurately if described as a 3D case.
Stiffening effects at the corners and nonuniform excavation procedures: When excavations are made in densely populated urban areas, accurate predictions of movements are desirable to rationally design appropriate support systems that minimize damage to surrounding utilities and buildings. While 3D analysis of the problem is now possible as the higher speed computer processors are now available. It is desirable to quantify the $3 D$ performance of an excavation to provide a baseline against which results of numerical procedures can be improved.

\section{NUMERICAL DATA}

\section{1. Geometric Approximations} Performing a 3D analysis of an excavation using a complex soil model is prohibitively expensive with given available computer capabilities. Many previous analyses simplify the excavation problem to plain 
strain geometry. This assumption can be a good approximation for linear excavations (e.g., subway construction), but will overestimate the midsection for the excavation geometry so the $2 \mathrm{D}$ analysis and $3 \mathrm{D}$ analysis have been performed and compared [2].

\section{2. The Two Dimensional}

\section{Model (2D)}

The 2D model of excavation of height, $\mathrm{H}$, and total CPW depth, Lp, as shown in
L1: is equal to twice of CPW length.

L3: is equal to twice of CPW length.

L: the half of excavation width.

\subsubsection{The Two Dimensional (2D) Element Used in Two Dimensional Model}

The type of element is "CPE6MP" which means a 6-node modified displacement and pore pressure, with hourglass control [3].

Fig. (1).

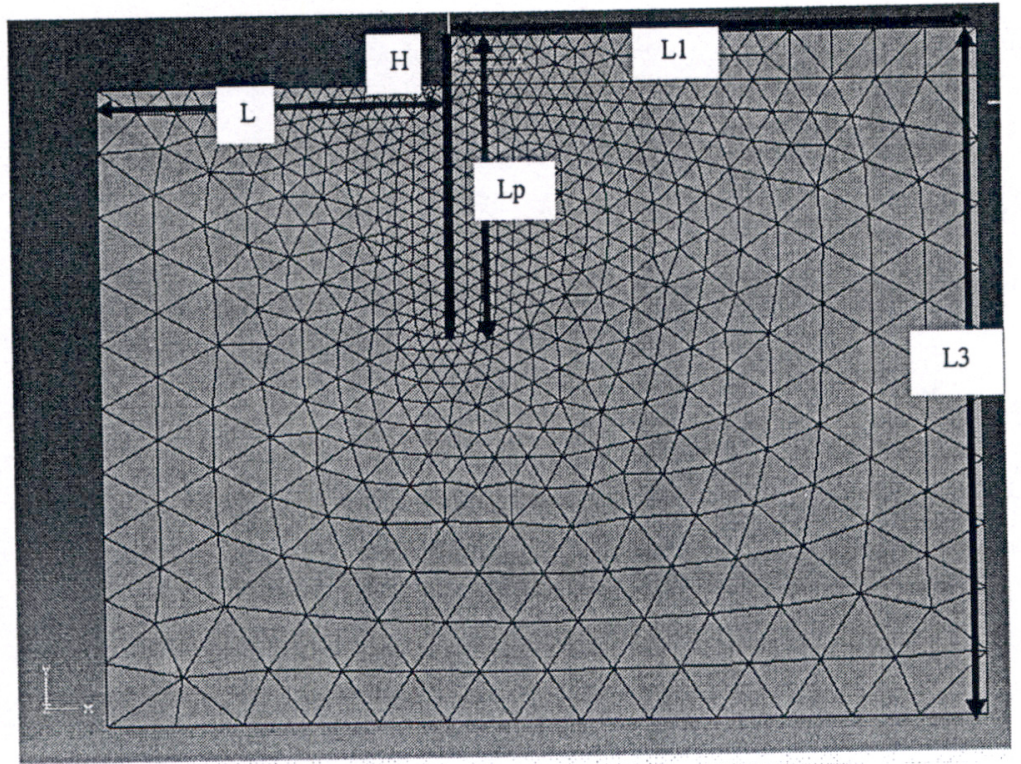

Fig.(1): The 2D model of the final excavation stage 
C. 4 DIF, A., Ibrahim, A. and Allam, R.

\subsection{The Three Dimensional Model}

The 3D model was represented by the height of excavation, total CPW depth "Lp" and the geometry of excavation "the width and the length" as shown in Fig.(2) with the axial symmetric geometry.

B: the half of excavation width. L: the half of excavation length.

\subsubsection{The Three Dimensional}

\section{(3D) Element Used in}

\section{Three Dimensional Model}

The type of element is "C3D10MP" which means a 10-node modified displacement and pore pressure tetrahedron, with hourglass [3].

\subsection{Contact Properties}

The Abaqus/CAE program supports a great variety of data concerning the contact surfaces in contact module [3].

A CPW contacts the soil with friction properties in cohesive soil with friction factor equal zero [4].

\subsection{Free Water Surface}

Abaqus/CAE program can model the pore fluid/stress analysis with coupled analysis. It uses the hydraulic conductivity for the CPW and the surrounding soil to flow the water. The pore pressure has no great effect on the CPW as it gives very small values due to the drainage from $\mathrm{CPW}$ so the assumption" undrained condition" in this study is good [5].

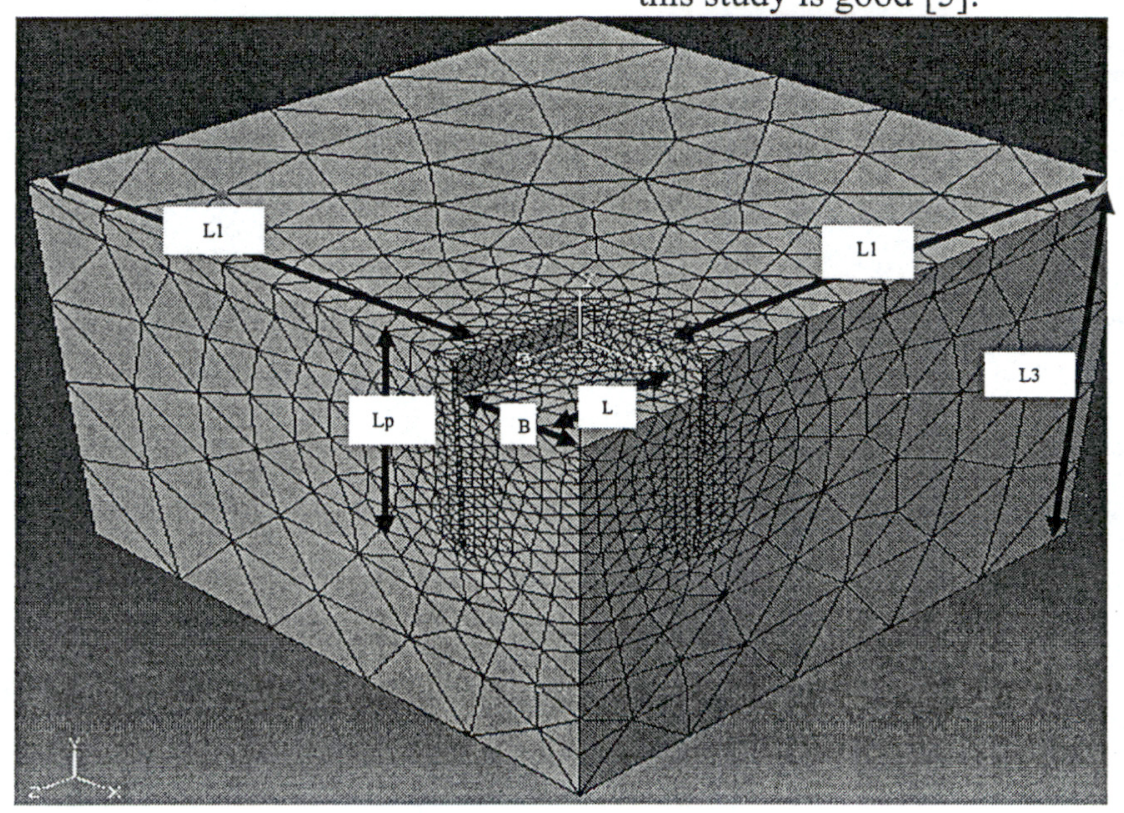

Fig.(2): The 3D model of the final excavation stage 


\section{ANALYSIS PROCEDURE}

\section{1. Materials Models}

Two dimensional (2D) model and three dimensional (3D) model assign Mohrcoulomb simulation for the soft clay as the traditional soil mechanics are based on this model [6].The CPW model has been taken as linear elastic behavior due to the low stresses that act on CPW. Determining the initial in-situ state of stress is an integral part of an excavation analysis which has been entered to the program by the geostatic stress initial condition. The body forces are applied in order to obtain the vertical stresses, while horizontal stresses are computed using appropriate values of $\mathrm{K}_{0}$ (lateral earth pressure coefficient at rest).

In Abaqus software, the initial states of stress and body forces are provided as an input for the program. The program allows for an arbitrary initial state of stress. The first step in the analysis checks the equilibrium between the applied forces, pressures and the specified state of stress using the true material properties of the different model components. The required input provides relatively easy for a level ground surface and horizontal soil layers [6], [3].

\subsubsection{The Soil Material}

Table.1 contains the properties of undrained soil in Mohr-Coulomb model for the clay which is used in $2 \mathrm{D}$ and $3 \mathrm{D}$ analysis [4], [7],[8],[9].

Table 1.The input parameters for the soil

\begin{tabular}{|c|c|c|c|c|c|c|c|c|c|}
\hline The soil & $\begin{array}{c}\mathrm{E}_{\mathrm{s}} \\
(\mathrm{Mpa})\end{array}$ & $v$ & $\Phi^{\circ}$ & $\sigma_{\mathrm{y}}(\mathrm{kPa})$ & $\alpha^{\circ}$ & $\mathrm{K}_{0}$ & $\begin{array}{c}\gamma_{\text {sub }} \\
\left(\mathrm{kN} / \mathrm{m}^{3}\right)\end{array}$ & $\mathrm{e}_{0}$ & $\mathrm{k}(\mathrm{mpd})$ \\
\hline Clay & 25 & 0.49 & 0.0 & 300 & 0.0 & 0.7 & 10.0 & 0.9 & 0.001 \\
\hline
\end{tabular}

\subsubsection{CPW Material}

As the stresses in the wall are small relative to the failure criteria of the concrete material, the elastic model is a good choice to simulate the $\mathrm{CPW}$ deformation as illustrated in Tables (2) and (3) [4]. 
Table2. The input materials for the CPW in 2D analysis

\begin{tabular}{|l|l|l|l|l|l|l|l|}
\hline The case & $\mathrm{H}(\mathrm{m})$ & $\mathrm{L}(\mathrm{m})$ & $\mathrm{D}(\mathrm{m})$ & $\gamma\left(\mathrm{kN} / \mathrm{m}^{3}\right)$ & $\mathrm{E}_{\mathrm{p}}(\mathrm{Mpa})$ & $v$ & $\mathrm{k}(\mathrm{mpd})$ \\
\hline 2D models & 3.0 & 18.0 & 0.4 & 22.0 & 1000 & 0.20 & $1 \mathrm{e}^{-12}$ \\
\hline Case $(1)$ & $\mathrm{L}=7,10,12,15,18$ and $24 \mathrm{~m}$ & \\
\hline Case $(2)$ & diameter $\mathrm{d}=0.2,0.3,0.4,0.5$ and $0.6 \mathrm{~m}$ \\
\hline Case $(3)$ & $\mathrm{H}=2,4$ and $6.0 \mathrm{~m}$ \\
\hline
\end{tabular}

Table 3.The input materials for the CPW in 3D analysis

\begin{tabular}{|c|c|c|c|c|c|c|}
\hline The case & $\mathrm{H}(\mathrm{m})$ & $\mathrm{L}(\mathrm{m})$ & 1 & 2 & 3 & \multicolumn{2}{c|}{4} \\
\hline 3D models & 3.0 & 18.0 & $20 * 20$ & $20 * 40$ & $20 * 60$ & \multicolumn{2}{|c|}{$80^{*} 20$} \\
\hline $\begin{array}{c}\text { Case (4) and (5):The site geometry } \\
\text { dimensions " length/width" }\end{array}$ & 1.0 & 2.0 & 3.0 & \multicolumn{2}{|c|}{4.0} \\
\hline \multicolumn{2}{|c|}{ Parameter } & $\mathrm{D}(\mathrm{m})$ & $\begin{array}{c}\gamma \\
\left(\mathrm{kN} / \mathrm{m}^{3}\right)\end{array}$ & $\begin{array}{c}\mathrm{E}_{\mathrm{p}} \\
(\mathrm{Mpa})\end{array}$ & $v$ & $\mathrm{k}(\mathrm{mpd})$ \\
\hline
\end{tabular}

\subsection{Different Penetration Depths} for CPW Effect on the Lateral

\section{Deflection}

Fig.(3) is constructed to represent the deflection versus the penetration depth for CPW piles $0.4 \mathrm{~m}$ in diameters, supporting excavation depth $(\mathrm{H}=3.0 \mathrm{~m})$ and surcharge load $=10 \mathrm{kPa}$ is found at the ground surface. The following notes for different penetration depths effect on the lateral deflection are remarked:

i. Short CPW piles have laterally entire movement while, the long CPW have great lateral deflection at the head only due to its large weight. This is clearly the weakness of soil.

ii. The long CPW have maximum head transition due to the ratio between the diameter and length ratio $(d / L=0.4 / 32.0)$.

iii. The intermediate $\mathrm{CPW}$ $(\mathrm{L}=10.0, \quad 12.0,15.0$ and $18.0 \mathrm{~m})$ have constant movement after excavation depth.

iv. The surcharge effect is greatly clear in long $\mathrm{CPW}$.

v. The best CPW length is 24.0 $\mathrm{m}$ as it has minimum lateral deflection to length ratio $((\Delta / \mathrm{L})=0.063)$. 
Lateral Deflection ( $\mathrm{mm}$ )

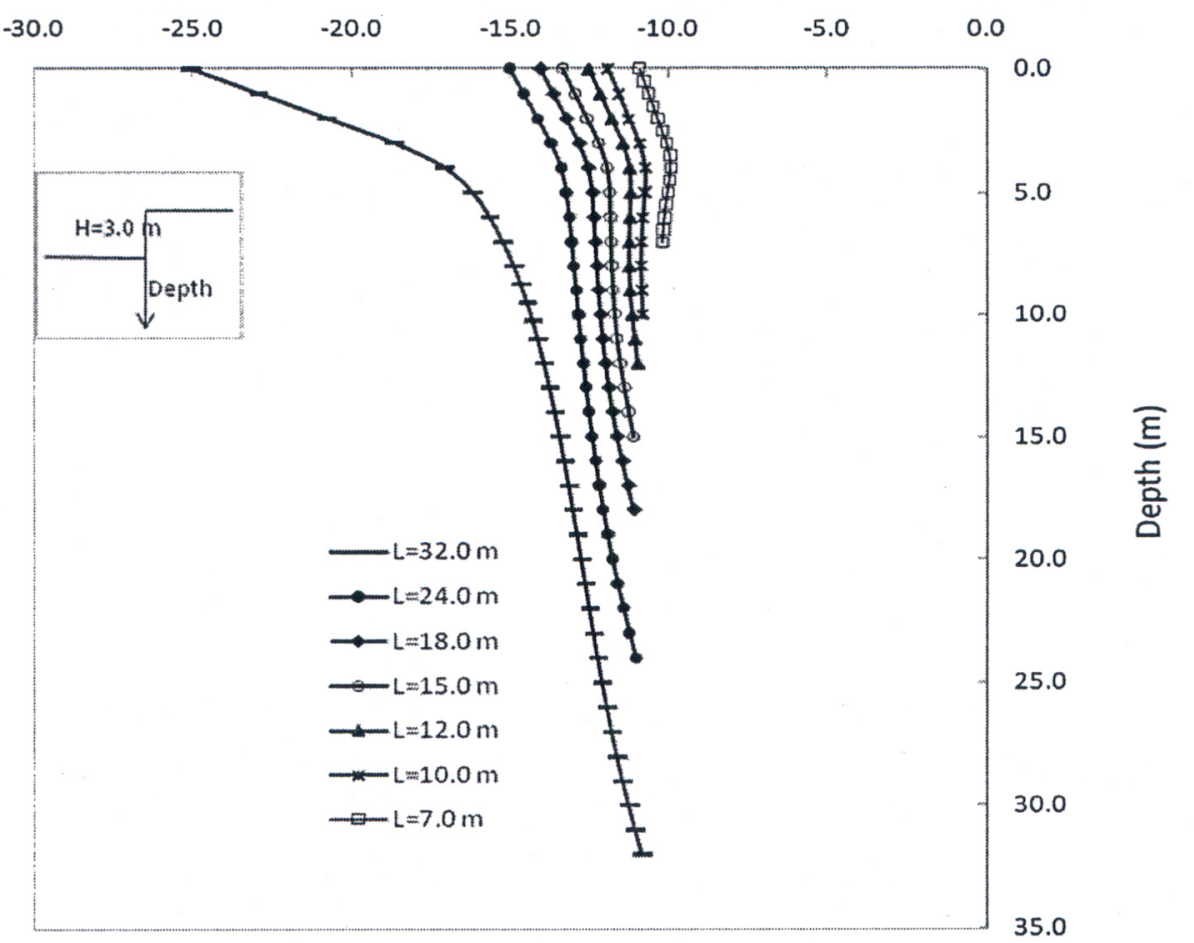

Fig.(3): The lateral deflection for different penetration depths

\subsection{CPW Diameters Effect on}

\section{the Lateral Deflection}

Fig.(4), for CPW (18.0) $\mathrm{m}$ in length and CPW is supporting excavation depth $(\mathrm{H}=3.0 \mathrm{~m})$ with variable diameters. The following comments on the effect of CPW diameters on lateral deflection were observed: i. The lateral deflection is approximately typical for all types.

ii. The large head transition is for small diameters.

iii. The head transition is approximately has the same value for all cases.

iv. The effect of $\mathrm{CPW}$ diameters is negligible for 
C. 8 DIF, A., Ibrahim, A. and Allam, R.

the lateral deflection but the

buckling effect for the long
CPW must be taken into consideration.

Lateral Deflection $(\mathrm{mm})$

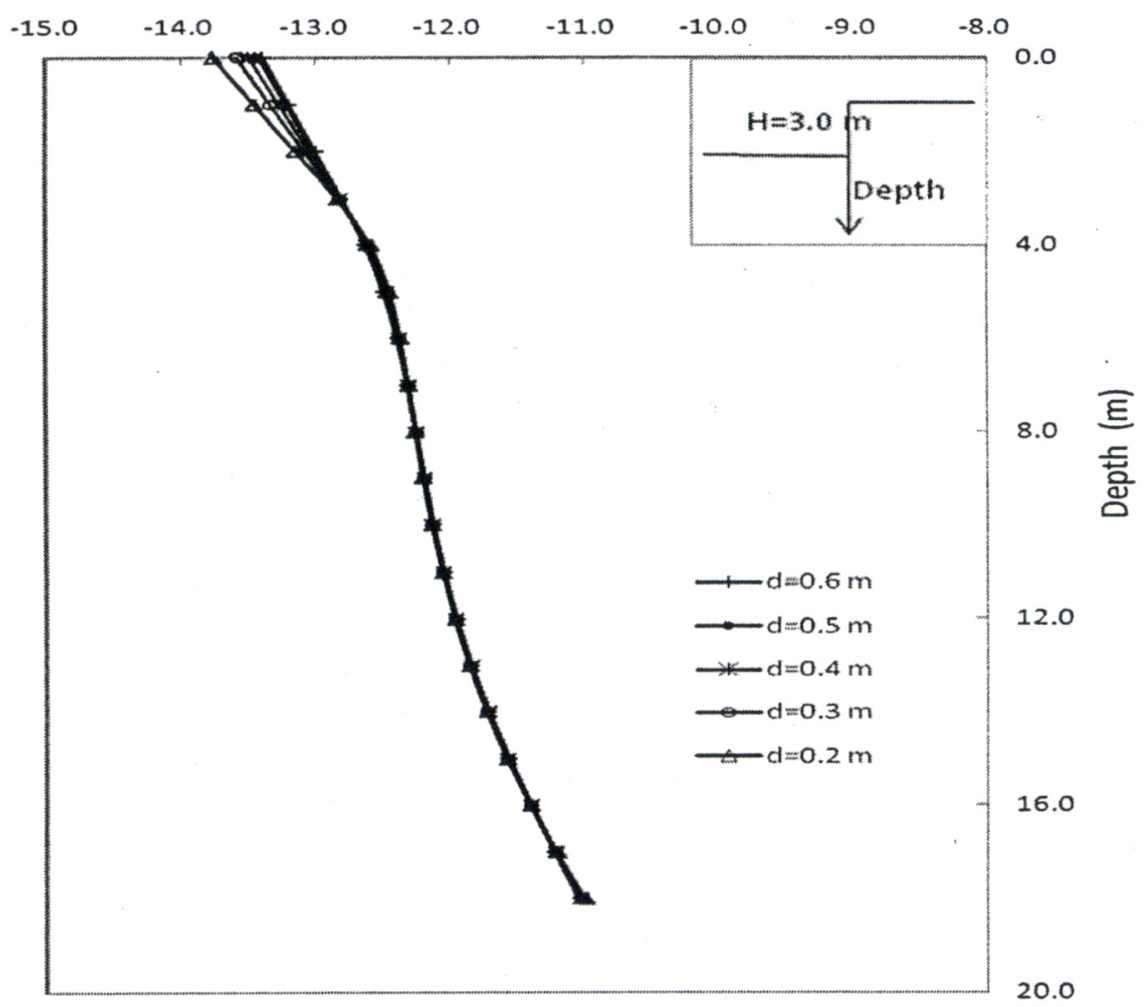

Fig.(4): The lateral deflection for variable CPW diameters

\subsection{Construction Stages Effect on} the Lateral Deflection

Fig.(5) includes the effect of construction stages on the lateral deflection for CPW with piles of diameter $(0.60) \mathrm{m}$ and total length $(\mathrm{Lp}=45.0) \mathrm{m}$, supporting excavation depths, $\quad(\mathrm{H}=2.0 \mathrm{~m}), \quad(4.0 \mathrm{~m})$ and (6.0m) respectively. From the curves, the following remarks are noticed:

i. The lateral deflection is increased by increasing the excavation depth.

ii. The lateral deflection for each stage is approximately twice the previous stage. 
iii. The weakness of soil make the retaining structure is moving entirely towards the excavation.

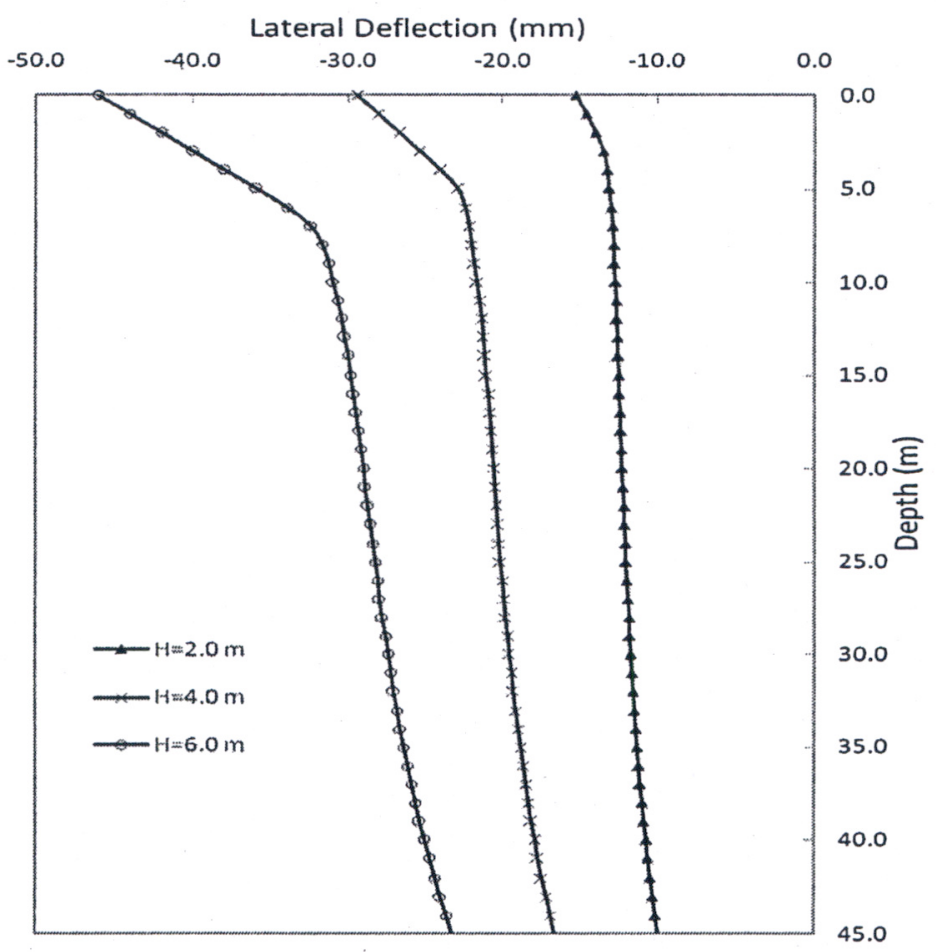

'Fig.(5): Construction stages effect on the lateral deflection

\subsection{Excavation Geometry Effect} on the Lateral Deflection for CPW

Fig.(6) includes the effect of $2 \mathrm{D}$ and $3 \mathrm{D}$ analysis with aspect ratio $(\mathrm{L} / \mathrm{B})$ is equal to $(1.0),(2.0)$ and (3.0) on the lateral deflection, $\mathrm{CPW}$ length is $18.0 \mathrm{~m}$ with constant diameter (0.40) $\mathrm{m}$, supporting excavation depth $(\mathrm{H}=3.0) \mathrm{m}$. From the curves, the following remarks are noticed:

i. 2D results give constant and small deflections.

ii. 3D results are almost constant and large as the effect of whole structure.

iii. The lateral deflection is almost the same for all $3 \mathrm{D}$ cases.

iv. $3 \mathrm{D}$ results are equal four times the $2 \mathrm{D}$ results. 
C. 10 DIF, A., Ibrahim, A. and Allam, R.

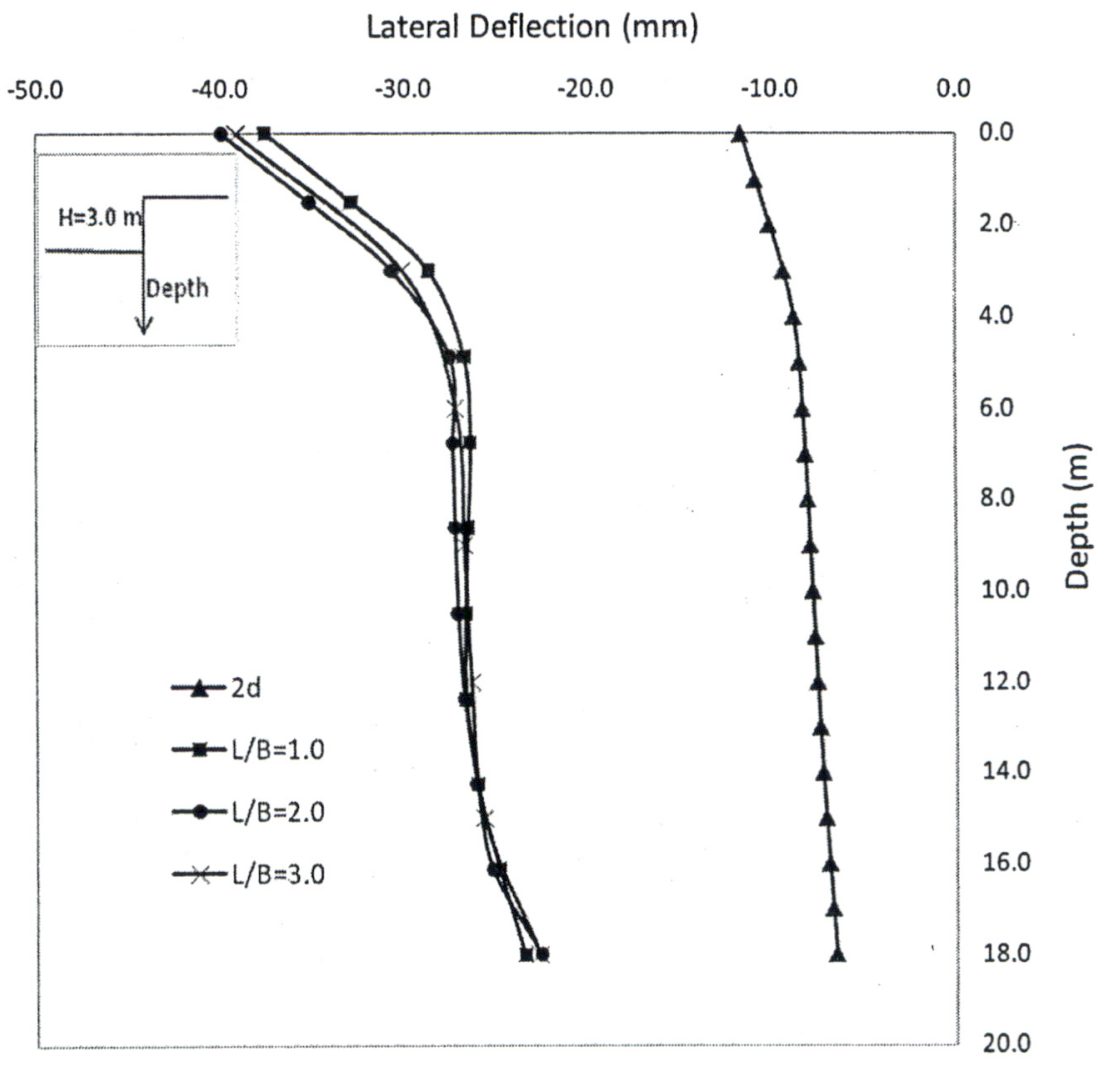

Fig.(6): The lateral deflection for 2D and 3D CPW Excavation Geometry

\subsection{Two Dimensional and Three}

\section{Dimensional Different CPW}

\section{Lengths Effect on the Lateral}

\section{Deflection}

Figure (7) includes the effect of CPW piles penetration depth in $2 \mathrm{D}$ and $3 \mathrm{D}$ analysis on the lateral deflection. CPW piles length is
(18.0) $\mathrm{m}$, constant CPW with diameter (0.40) $\mathrm{m}$, supporting excavation depth $\mathrm{H}=3.0 \mathrm{~m}$ in $2 \mathrm{D}$ analysis. 3D analysis for site $(20.0 \mathrm{~m} * 20.0 \mathrm{~m})$ and CPW lengths, (12.0) $\mathrm{m},(15.0) \mathrm{m}$ and $(18.0 \mathrm{~m})$. From the curves, the following remarks are noticed:

i. The CPW Deflection in 3D results is large for long 
CPW as its weight and its length.

ii. The CPW Deflection in 3D results is equal to three times of the $2 \mathrm{D}$ results.

Lateral Deflection $(\mathrm{mm})$

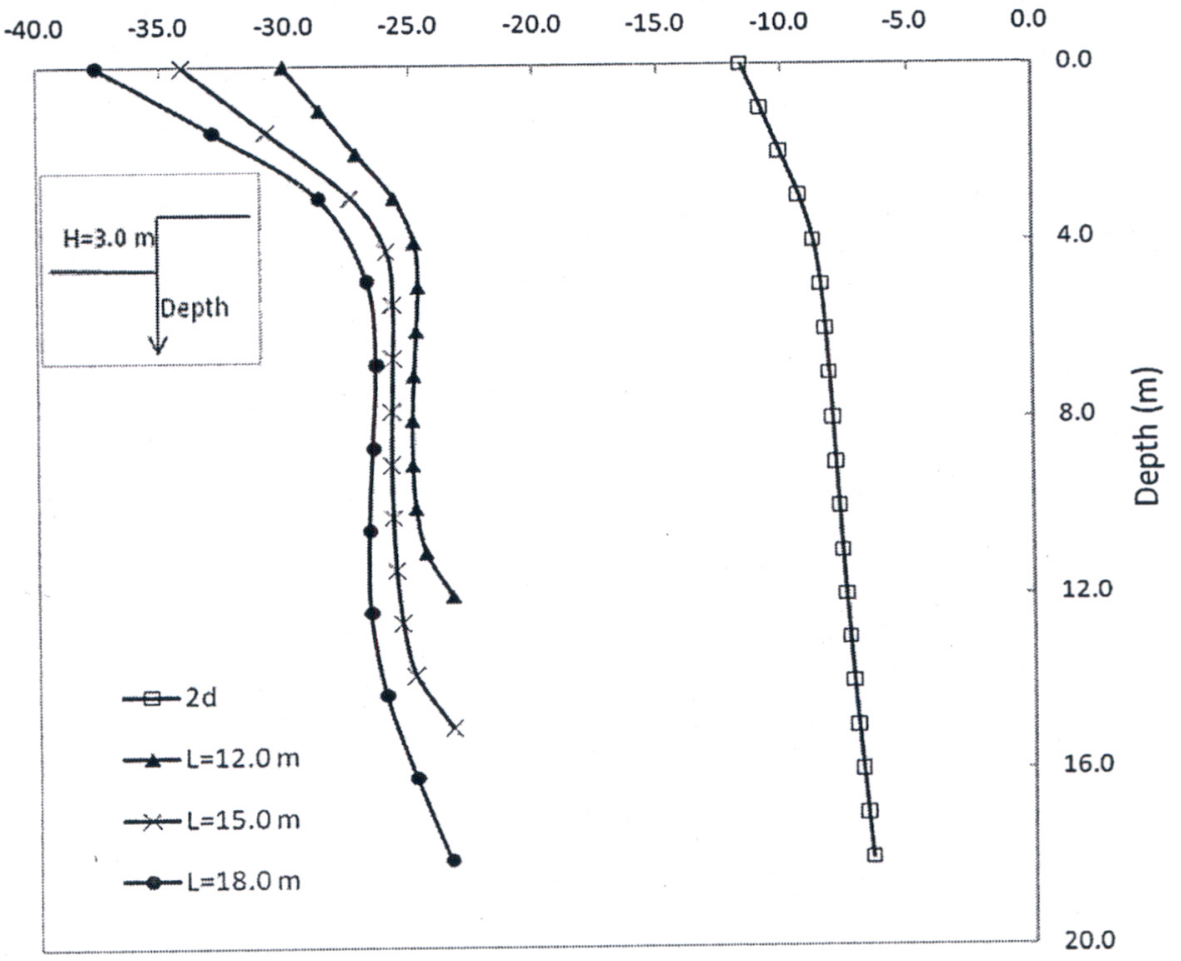

Fig.(7): The lateral deflection for $2 \mathrm{D}$ and $3 \mathrm{D}$ different $\mathrm{CPW}$ lengths

\section{CONCLUSIONS}

In this study, 2D and 3D finite element analysis were used to determine the lateral deflection for CPW in soft clay. The effect of CPW (cantilever pile wall) length, the CPW diameters, construction stages and 3D geometry, of $\mathrm{CPW}$ on lateral deflection have been studied. The following conclusions could be drawn from the study:

i. The behavior of soft clay soil 
is very complicated and varies with the weight and the dimension of CPW.

ii. The $2 \mathrm{D}$ results do not reflect the real CPW behavior. This is due to neglecting the own weight effect.

iii. 3D results take the own weight of the whole structure (CPW) as stabilizing factor so the CPW haven't been moved

\section{REFERENCES:}

[1] Richard, J.F., "ThreeDimensional Effects for Supported Excavations in Clay." ASCE, Vol.133, No.1; 130-50, 2007.

[2] Chang-Yu O., Pio-Go H.," A simplified method for predicting ground settlement profiles induced by excavation in soft clay" Computers and Geotechnics, Vol:38, Issue 8, December 2011, Pages 987-997.

[3] ABAQUS/CAE User's Manual v6.8, Simula Company, Dassault S., 2008

[4] Egyptian code for soil mechanic, foundations design and implementation, ECCS-202/7 and 3, v6, 2001.

[5] Youssef, M.A., "Analysis of Deep Excavations in Clay", $\mathrm{PhD}$. in civil engineering, entirely all over the length.

iv. The diameters of $\mathrm{CPW}$ have no effect due to the weakness of the soil.

v. By increasing CPW lengths, the lateral deflection in $2 \mathrm{D}$ results increases.

vi. Three dimensional results for the lateral deflection are higher than the two dimensional results by three times.

Massachusetts Institute of Technology, 1992.

[6] David, M.W. "Geotechnical Modeling" E\&FN Spon, v2.2, 2004.

[8] Hans-Georg, K. and Berhane, G. " Excavations and Foundations in Soft Soils", Springer-Verlag, B.H., Netherlands, 2006.

[8] Hamdy, F., and Fei C.,et.al "Two-dimensional base stability of excavations in soft soils using finite element method" Computers and Geotechnics 30 (2003) 141163.

[9] Hamdy, F., and Fei C.,et.al " Three-dimensional base stability of rectangular excavations in soft soils using FEM" Computers and Geotechnics 31 (2004) 67-74. 